\title{
A Discrete Choice Analysis Of Smallholder Farmers' Preferences And Willingness' To Pay For Weather Derivatives: Evidence From Ethiopia
}

\author{
Davide Castellani, University of Bergamo, Italy \\ Laura Viganò, University of Bergamo, Italy \\ Belaynesh Tamre, Wolaita Sodo University, Ethopia
}

\begin{abstract}
The ability of Ethiopian farmers to deal with rainfall risk is scanty due to the extension of land plots and incomplete and inefficient financial markets. Traditional drought insurance is flawed by information asymmetries, high administrative costs, and non-diversifiable risks. Insurance based on indexes is a promising alternative. Working on 120 rural households, we estimate the willingness to pay for a drought weather derivative through a mixed logit model allowing for random preferences. The results suggest that the premium, indemnity, and perceived frequency of drought are important determinants of the take-up. Apparent inconsistencies in behavior can be interpreted as rational choices.
\end{abstract}

Keywords: Index-Based Insurance; Weather Derivative; Microfinance; Ethiopia

\section{INTRODUCTION}



ural households and individuals in developing countries are vulnerable to shocks, be they man-made or natural disasters. Even other adverse, non-catastrophic conditions may challenge farmers and limit their potential to develop and innovate. Rainfall variability is a major problem as agricultural activity is almost all rain-fed in remote rural areas. Several traditional strategies are followed by households to deal with this vulnerability: reducing exposure, cumulating money buffers, looking for credit, implementing diversification, or participating in informal insurance mechanisms. Some of these strategies may not be effective (Fafchamps, 1999). For example, informal or self-insurance mechanisms may be limited by the dependence on co-variance of risks and may show certain rigidity towards changes (Dercon, 2003).

Formal insurance is often considered a challenge both for farmers and for insurers. Brown (2001) recalls that the demand for formal insurance depends at least on the will of customers to reduce their vulnerability, on their ability and willingness to pay (WTP), and on the suitability of the contract. On the other side, insurers judge the opportunity to offer insurance on the existence of basic implementation conditions. As Brown (2001) states, beside the need for large enough numbers of potential customers, for the possibility to estimate price and diversify risk, and for efficient delivery channels - often lacking elements in rural areas - the insurance contract should be conceived so that the information asymmetries are under control. As in the case of lending, the moral hazard can be reduced in cooperative insurance agreements, thanks to peer control (Viganò et al., 2007). Differently from the case of lending, however, the limited size of cooperative schemes in a poor rural context may make insurance unfeasible. Formal insurance options may then be available if they succeed in proposing insurance contracts that are effective with respect to the achievement of their financial sustainability and to the satisfaction of customers' preference, combining the product with a suitable delivery process. However, this is not an easy task. 
Crop insurance has been widely studied and many examples show how difficult it is to offer suitable products as failures are often reported in the literature, especially in public projects led more by development goals than by sustainability (Viganò, 2002). A frequent distortion of insurance schemes based on estimated crop losses is moral hazard, which loosens farmers' commitment to production (Hess et al., 2002).

Conversely, relatively new products base the compensation on the value taken by properly designed, standardized, and verifiable indexes (precipitation, wind speed, temperature, solar radiation), which have a statistical correlation with crop yields and cannot be influenced by the customer behavior (Bryla et al., 2003). These contracts minimize the ex-post verification costs (Hill \& Robles, 2011). The prevailing contracts are based on area yield, livestock, weather indexes, or weather derivatives (Hess et al., 2002; Skees, 2003). The first type simplifies by assuming that homogeneous areas can be localized and the average yield loss is applied to all farmers of the same area, although some adjustments are possible for single farmers (FAO, 1992, 2001; Skees et al., 2002). Similar average computing applies to livestock protection. In both cases, payment is due if the area losses exceed a given threshold. Weather index insurance is based on the correlation between natural phenomena and agricultural yields and foresees compensations if the index exceeds or falls short of (depending on the type of risk) a given threshold. Computing the correlation and estimating the payment due for each point gap between the threshold and the actual measurement are complex processes, the appropriateness of which depends on the accurate choice of the period of observation, the quality of the meteorological data, and data on farmers' historical production. Specific adjustments allow compliance with farming seasons or with other customer characteristics and preferences (Hess, 2003; Skees, 2003). A similar outcome can be assured by using weather derivatives as, despite the different contractual form, they also foresee a payment based on a tick size multiplied by the gap between the index and the actual measurement of the weather variable (Hess et al., 2002; Skees, 2003). While Berg et al. (2004) stress that index-based insurance is more often used in the case of catastrophic risk exposure, weather derivatives are also increasingly applied to the same target. A difference portrayed by Hill and Robles (2011) is related to the greater suitability of weather derivatives for different customer preferences than standard index insurance and to their higher liquidity.

These contracts are expected to reduce farmers' revenue volatility. Hill and Robles (2011) quote examples portrayed by Hess and Hazell (2009) and mention implementations in Ethiopia for haricot beans and teff, in India for groundnuts and multiple crops, in Malawi for groundnuts and tobacco, in the Philippines for rice, and in Peru for cotton. However, despite their potential usefulness, the insurance uptake still seems meagre (Clark \& Kalani, 2011; Sarris, 2013) and critical points are stressed. They are related to technical matters, such as the higher basis risk to which customers are exposed, and to the cost of these contracts. ${ }^{i}$ Besides, the lack of appropriate delivery channels or the high delivery cost may impede their development. One major obstacle envisaged in these contracts refers to farmers' willingness to pay the premium and, more generally, to bear the total transaction costs. The attitude, in turn, depends on the advantage offered by the insurance. One can reasonably expect that the more the product reflects the overall risk exposure, the lesser is the basis risk perceived, and the fewer the alternatives, the higher could be the willingness to pay a given price (or to bear a given total purchase cost). Put in the reverse way, the lower is the risk exposure; the higher is the basis risk or the competition in supply (formal and informal), the lower the price that the farmer wants to pay. Regarding the basis risk, it seems that offering compound index products (Elabed et al., 2013) or combining simple weather derivatives so that more than one risk is included (Hill et al., 2011) contributes to reducing the impact of the basis risk and to improving the WTP. Another related obstacle mentioned by Sarris (2013), quoting Bryan (2010), is the "ambiguity aversion," which makes it unappealing for customers to buy a financial product based on a probability distribution they cannot duly assess. These are just a few examples of the influence of several factors on the willingness to buy index-based insurance or a weather derivative. The remaining part of the article is organized as follows. The next section explores some outcomes of studies on the determinants of the WTP, while section 3 offers a brief overview of experiences and studies in Ethiopia. Sections 4, 5 and 6 describe the research experiment, the empirical approach, and the employed control variables, respectively. The discussion and interpretation of the results are provided by section 7. Section 8 simulates the market shares of hypothetical standardized products. Section 9 concludes.

\section{WILLINGNESS TO PAY IN THE RECENT LITERATURE}

Several studies, especially in recent years, have attempted to gain a better understanding of the factors behind the willingness of rural farmers in poor countries to pay for insurance. Differently from a similar exercise run 
in a country or for a population segment in which insurance is already widespread, inquiries regarding target segments when insurance products seldom exist cannot replicate real situations and are based on hypothetical products; the answers obtained do not necessarily represent actual behaviors as households may behave very differently in the real world (Breidert et al., 2006, as quoted by Hill et al., 2011). Nevertheless, WTP studies contribute to improving the offer of insurance, help to fine-tune the design and provision of insurance products and identify the most suitable markets and the limiting factors perceived by potential customers, and provide an estimate of the price elasticity. For a more general plan, the welfare implications of the use of crop insurance can be assessed, which may suggest to policy formulators better ways to promote access (Hill et al., 2011; Sarris, Karfakis, \& Christiaensen, 2006). Several factors affecting WTP are outlined by the different studies, pertaining to the customer characteristics or the type of suppliers involved; the studies differ in the emphasis put on such characteristics as well as in the analytical approach. Below, the main findings are presented. A necessary caveat relates to the fact that these studies differ regarding the type of product considered (index-based policy or weather derivative), which makes comparisons less obvious. Another warning refers to the efficacy of the experiments which is challenged in some studies when a limited correlation is found between the stated and revealed preferences (McIntosh et al., 2013), although for Norton et al. $(2011,2012)$ this is not the case.

Some objective factors affecting WTP are highlighted by Hill and Robles (2011), who find that farmers with poorer soil quality buy more insurance. Sakurai and Reardon (1997) stress the dependence of the demand for drought insurance on the different agro-climatic zones, which implies different risk exposures (also confirmed by Hill \& Robles, 2011). The features of different natural hazards are also important factors for the insurance participation decision. Patt et al. (2009) point out that most studies focus on economic explanations (such as the size and timing of the premium and the potential payouts, utility and risk aversion), while behavioral factors (emotions and trust in the suppliers, in the product, or in oneself) may matter more and imply pursuing customer's satisfaction rather than optimization. In fact, the customer's personal preferences and entrepreneurial characteristics, as in any other financial transaction, may play a major role in determining the WTP.

The attitude toward risk is a key factor. Hill et al. (2011) confirm a positive relationship between perceived risk exposure and WTP for insurance. Fraser (1992) aims to capture the impact of insurance on the Australian wheat producer's expected income and variance. He finds that WTP is relatively insensitive to price variability but strongly positively related to yield variability. The degree of risk aversion may induce the farmer to buy insurance; however, the lack of knowledge coupled with risk aversion may induce caution. The effect of risk aversion on WTP may actually have the opposite sign, sometimes counter-intuitively as, under specific conditions, in Hill et al. (2011) for Ethiopia. Giné et al. (2008), in their study on Andhra Pradesh, India, find that risk-averse households are less likely to purchase only if they are unfamiliar with the insurance contract or with the dealer.

Akter et al. (2009) state that the demand for crop insurance varies according to several factors related to different risk management strategies: area characteristics, the breadwinner's occupation, land ownership, and farm size. Gautam et al. (1994), in their study in Tamil Nadu (India), apart from risk attitude, empirically test for the joint hypothesis of risk avoidance and welfare smoothing, with the aim of studying the latent demand due to inadequate risk management strategies. Their results prove that this demand is high with a willingness to pay $13-17 \%$ of income as the premium. Sakurai and Reardon (1997), who study drought insurance in Burkina Faso, show that the demand depends, among other things, on how households manage risk ex ante and ex post: wealthier, more selfinsured farmers demand less formal drought insurance. Negative significant effects of off-farm income and livestock holdings on the demand for formal insurance emerge, as both allow the implementation of self-insurance mechanisms and diversification. Nevertheless, this depends on the stratum of the population analyzed; for example, in the upper stratum, neither off-farm income nor livestock holdings have a significant effect.

The effects of wealth on WTP may, in fact, be ambiguous. Patrick (1988), in a study on rainfall insurance for Australian wheat producers, finds higher rainfall insurance premiums associated with larger plots and with more conservative farmers and a higher level of net worth associated with lower premiums. Assets may provide a buffer against income shocks; however, a larger amount of assets may induce the farmer to take risky decisions and, therefore, to buy insurance. Akter et al. (2009), in their research on natural disaster risks in Bangladesh, find a positive influence of land holdings on insurance uptake. This outcome shows that land extension may not necessarily lead to better diversification and households that depend primarily on crop farming for their livelihood 
exhibit a greater demand for crop insurance. Ambiguous behavior related to wealth is shown by Clarke and Kalani (2011), who find the highest take-up ratio with intermediate wealth levels; in fact, farmers who are too poor may have nothing to lose and do not need to insure, while very rich farmers may have other options than insurance (Castellani et al., 2013).

As for the case of wealth, cash holdings may also have contradictory roles. Cole et al. (2009), in their study on Andra Pradesh and Gujarat, show that the insurance demand is sensitive to cash on hand. They record an increase of $34.5 \%$ in participation by providing the household with cash, which is a much larger effect than cutting the price by $22-46 \%$. However, cash obtained by other sources may negatively affect WTP. Indirectly linked to cash holdings is the existence of credit constraints; in Giné et al. (2008), credit constraints appear to be an impediment to the purchase of insurance, possibly because they limit the cash availability. On the other side, being indebted could negatively affect WTP if all the cash is used to repay the loan.

The effect of aid is controversial. While aid offered (especially in cash) by the donors or the government may increase the farmers' financial capacity to buy insurance, demand distortion may take place. In fact, as Sarris (2013) points out, in different studies, subsidies or initial endowments in experiments are the main element inducing farmers to buy insurance, given the quite frequent complaint of a lack of cash. This fact may have distortions on farmers' decisions and in the interpretation of the results and may even compromise the possibility to implement real insurance schemes under market (not subsidized) conditions. Sakurai and Reardon (1997) find that public food aid, causing moral hazard, has a significant negative effect on the demand for drought insurance and discourages selfinsurance as well.

Besides individual, household, or land characteristics, how insurance is offered may also make a difference, both in terms of accessibility and in terms of knowledge and trust on the part of the potential customer. Cole et al. (2009) register a positive influence on WTP for insurance of the association of the insurance product with individuals or symbols that the household trusts; in the Andhra Pradesh case, trusted local individuals endorsing the contract increase the probability of buying the contract by $40 \%$. They notice that sale strategies, such as marketing visits, can help to build trust and knowledge about the product, in spite of the fact that other "subtle marketing treatments" have no statistically significant effect on insurance participation. This result is also confirmed by Hill and Robles (2011) in relation to visits from extension agents. Another important fact outlined is the role of social links, as potential customers are more likely to participate if they subscribe to the contract as a group. In the same sense, Hill et al. (2011) examine the changes in demand based on the offer of insurance to traditional risk-sharing groups in Ethiopia. They find that group insurance may make individuals decide to subscribe to a contract that they would not buy individually, especially those people who have more difficulty in understanding the contract terms. However, this is not the case when the trust level is generally low in the neighborhood. Patt et al. (2009) believe that trust could also be built through experiments conducted before the launch of a real product.

In fact, knowledge and understanding of the contract terms are not granted among the potential recipients but may make the difference for their choices, as reported by Akter et al. (2009), who find that greater familiarity with insurance (related to education) makes purchases more likely. Giné et al. (2008) quote young people as an example of customers who deal more easily with such products, experiencing fewer cognitive costs of understanding. However, they do not find a significant effect of education on take-up, contrary to previous studies. Knowledge is probably favored by a higher level of education (Hill et al., 2011), confirming why the young react positively to insurance. Cole (2009), on the contrary, finds that the provision of a small amount of additional financial education is not statistically significant in influencing WTP, as a consequence of possible sufficient existing education in the sample or, on the contrary, of inadequate education. Patrick (1988) explains a negative effect of education on take-ups with lower risk aversion.

Knowledge may, in fact, be more or less adequate depending on the complexity of the contract, defined by its conditions: price, maturity, delivery methods, chosen index, triggers, or thresholds. Dalal and Morduch (2010) state that, based on behavioral patterns, sometimes just small adjustments to products or delivery methods or to other characteristics of the schemes enable the potential customer to understand the product better and be more willing to buy it. Among other things, they recommend taking the context into account, keeping the products simple, and 
making sure that people appreciate the relevance of the contract; overall, they suggest that some of the marketing strategies applied to other fields should be applied to the offer of microinsurance.

The contract conditions themselves directly affect WTP, and, quite often, their effect is combined. Cole et al. (2009), while estimating the price elasticity of the demand for rainfall insurance as between -0.66 and -0.88 , state that what matters are the combination of the price and the suitability of the index chosen, or other contract conditions. In the introductory section, basis risk amplitude is quoted as one important factor (this is supported by Hill et al., 2011). This is empirically tested by Fuchs and Wolff (2011), in a study on weather index insurance in Mexico; they find basis risk to be one of the major problems in product design and outline the importance of setting suitable thresholds upon which to compute the triggers and compensations. In a pilot study in Ethiopia by Volpi (2005), farmers explicitly express the fear of a low correlation between the rainfall patterns at the weather station and those in the area where they have their plots; by being aware of multiple risk exposure they are not persuaded by single-risk protection if the price is not low enough.

However, even suitable contracts may have some negative side effects, such as a disincentive to cultivate non-insured crops or to improve the technology systems such as irrigation (Fuchs \& Wolff, 2011). In fact, while positive overall implications of the adoption of crop insurance on welfare are often deemed relevant in order to build a system of public incentives for the suppliers and the buyers, negative implications should be considered as well. Distortions in behaviors are probably more likely to happen if the contract is subsidized. Subsidization (a possibility foreseen by Hill et al., 2011) undoubtedly makes it more convenient to pay for insurance than to put in place alternative risk management methods. Conversely, from a market perspective, the insurance cost, reflecting the price of risk, must be set in such a way that makes the two alternatives comparable or at least not so different in economic terms.

The ones quoted are just some of the possible patterns in exploring the dynamics of WTP for crop or drought insurance in a poor rural area. Some authors try to conceptualize the demand for insurance according to different analytical frameworks, namely considering insurance as a stand-alone hedging instrument, as a financial innovation, or as an input into a portfolio risk management strategy (Hill et al., 2011). Some of the cases of controversial effects mentioned above can indeed be explained by different frameworks and new findings may come from further analyses. Our study aims to shed some further light on the topic, considering the Ethiopian case. Before presenting the detail of the empirical research, some previous studies conducted in Ethiopia are analyzed.

\section{WEATHER AND CROP INSURANCE IN ETHIOPIA}

Ethiopia is of special interest in relation to the introduction of index insurance, being exposed to several hazards: besides droughts or heavy rains, pests or animal diseases often threaten production.

Hill and Viceisza (2010) asked a sample of 261 Ethiopian households of Silte Woreda (Southern Ethiopia), chosen within iddirs (local risk-sharing groups), to take part in a game and decide whether they were willing to purchase fertilizers. They then introduced a weather index insurance contract coupled with a grant to purchase it. The experiment was organized in 12 sessions over a week: 6 without and 6 with insurance. The estimated positive changes in fertilizer purchases depending on insurance mean that the latter influences the decision to take more profitable risks (with effects on technology adoption). Since purchases may also depend on other factors, such as past weather conditions (in turn, affecting wealth and the perception of usefulness of fertilizers), and on socioeconomic factors (liquidity constraints, peer effects, and trust, as well understanding the products), a nearestneighbor matching estimation was conducted to control for some of these factors. Findings are a positive effect on the purchase of fertilizers of insurance and understanding of the contract, risk aversion, and acquired experience with fertilizers.

Clark and Kalani (2011) conducted an experiment on WTP for index insurance and for indemnity insurance, to analyze whether these choices are rational, how to explain behaviors according to a utility theory, and whether insurance is better sold to risk-sharing groups. They used data on a sample of 378 households from the Ethiopian Rural Household Survey (ERHS) ${ }^{\text {ii }}$. Farmers were instructed, through visual aids, to make 3 decisions each time but were paid for only 1 of them and compensation was set in order to obtain an average expected daily earning 
higher than the daily wage. The cases of individual insurance, group insurance, and index insurance represented different sessions. The initial endowment was 65 ETB (Ethiopian Birr), with a potential loss of 50. Having included several explanatory variables, Clark and Kalani (2011) show a non-linear relationship between wealth (proxied by livestock ownership) and take-up of index insurance, with the highest frequency in the intermediate wealth levels. Contrary to other studies, education and knowledge do not increase the take-up of indemnity or index-based insurance. Historical risk exposure positively influences the take-up of indemnity insurance. Participation in risksharing groups has the same effects on both types of insurance. A dummy representing the ability to obtain emergency cash of 100 ETB is positively associated with the take-up of index insurance, probably because it is a proxy for the higher degree of familiarity with informal risk-sharing methods and insurance. In general, they find a high take-up rate for index insurance, with higher than optimal coverage levels, and no evidence of lower than rational levels. Their point is that the behavioral explanations offered for the low take-up rate of other studies could be weak and if farmers buy few contracts it is just a rational decision due to the type of product offered and could be even lower.

In Hill and Robles (2011), the basic idea is that farmers are diversified in their production and preferences and need to be offered diversified insurance contracts. They in fact maintain that offering each farmer a combination of weather derivatives is better than offering an index insurance, which is somehow standardized because it is often based on "a weighted combination of indexes with predetermined triggers designed to be a good hedge for an average farmer of a specific crop in a certain locale" (p. 1). Lack of customization and flexibility may hamper the adaptability of products to farmers. Farmers are different; in order to diversify among members of the same risksharing group, they may even make different production decisions from their neighbors. The study is based both on a real-time experimental game and on a subsequent real purchase. The work was conducted in Silte Woreda; 406 households were surveyed in the experimental game, in 2009, and 480 households in the insurance pilot offer, in 2010. The offer included 6 securities ( 2 for each of the 3 main months of the rainy season), with a severe and moderate loss cut-off based on the records of a local weather station. The rainfall pattern foresaw 2 securities out of 6 to pay. Each security had a fixed payout of 100 ETB and an expected value based on historical data. Endowments of between 30 and 60 ETB per person were randomly assigned to farmers, who were free to use or keep them. The costs transferred to the farmer in the case of a combination of weather derivatives were also considered as a trade-off element against greater flexibility. The farmers were checked with a follow-up survey. The take-up rates were extremely high (almost the entirety), thanks to the endowment as well. In 2010, a similar product was offered by a local insurance company, although for larger amounts of pay-offs (500 ETB) and the farmers had to pay with their own money. The take-up was lower for the participants in the experimental game, despite the payment received. Even accounting for the technical differences in the contracts, the authors question the validity of the experiments. They outline that the leaders of iddirs bought on behalf of their members in the experiments; these choices are considered as one take-up even if they benefit several farmers. To some extent, iddirs operate a sort of standardization, which is actually meant to be avoided. Concerning the analysis of farmers' choices, the variations depend on several factors, among which are the type of crop, the soil quality, and the presence of extension services. The study is not really conclusive, as the authors admit, but allows them to answer the research questions.

The study by Hill et al. (2011) ${ }^{\mathrm{iii}}$ is based on a study of 1,400 Ethiopian households tracked for 15 years as part of the ERSH. The 2009 round includes a module on willingness to pay for weather insurance, so the analysis focuses on the demand for weather insurance based on the products' and farmers' characteristics. Insurance contracts are more likely to be bought by educated potential customers, who are wealthy and proactive, or by people with higher risk exposure or greater risk aversion. Distribution through local risk-sharing groups is preferred in order to optimize the risk management by combining informal risk sharing and insurance depending on the levels and types of risk (the studyrecalls Clarke \& Dercon, 2009; Dercon et al., 2010). The basis risk was detailed and control questions were asked to make sure that the respondents understood the weather station measurements and compensation; the lack of trust or of understanding were minimized. The scheme foresaw a payment of 1,500 ETB when the rainfall falls below a given threshold; the premium suggested ranges between 10 and 40 ETB. More than $80 \%$ of the respondents expressed the will to buy insurance, with individual and group distribution methods accounting for about $50 \%$ each. Refusals to buy are linked to the fear of not being able to pay or the lack of need. Although basis risk was present and negatively perceived by an estimated 30\% of farmers for purchases beyond the first year, most farmers stated to be willing to buy in future years, despite not receiving compensation during the first one. The estimates of risk aversion, time preference, and the possibility to count on neighbors or the community 
for help in the case of shocks as well as sources of finance for emergency (credit, sale of assets, participation in emergency insurance groups, such as the iddir, or remittances) were considered. Detailed questions were asked on the shock exposures and the rain expectations to compute the probability of occurrence. Individuals' exposure to risk was estimated on consumption levels. The authors developed a basic model of insurance demand including price, risk aversion, basis risk, and wealth as variables. WTP is found to be negatively affected by price and positively affected by risk aversion (this outcome is somehow controversial). Another finding is that consumption levels are good predictors of the demand for insurance. Basis risk is proxied by self reported rainfall shocks and distance from weather stations; but only distance shows a significant and negative effect on demand. Besides, higher risk exposure increases WTP. While admitting the ambiguity of wealth effects, the conceptual model shows that WTP increases with wealth. The model was then extended by including other variables that could explain the purchase of insurance (age, sex, schooling, self-efficacy - confidence in one's capability to change one's life, time preference, household size, and access to financial institutions). A negative effect on WTP is caused by the attributes of being old, less educated, and female; the opposite occurs for access to financial services. Self-efficacy increases WTP, which is probably related to being prone to innovate. The results related to the preference for purchasing through iddirs - and their link to the trust issue - were reported in the preceding section.

Norton et al. (2012) $)^{\mathrm{iv}}$ implemented some experimental games in Tigray in 2010, within the Horn of Africa Risk Transfer for Adaptation (HARITA) project ${ }^{\mathrm{v}}$. The aim was to compare different choices among the options for allocating an initial endowment of 70 ETB: taking the drought index insurance, investing in simulated savings accounts, participating in risk-sharing groups, or holding cash. The second and third options were offered with a bonus of 10\%. Insurance was proposed in an identical format to the existing products with 2 frequencies of payouts (in 3 or 5 years) based on the observed rainfall. For an allocation of 5 ETB, 10 ETB (high frequency) or 15 ETB (low frequency) are paid in the worst years. One-third of the payment is ideally allocated to loadings even though for simplicity a $50 \%$ loading is used. The high-frequency insurance may be considered more aggressive, given the greater contributions required for the same payout in one year in both cases. Practice rounds were organized with representation of rainfall probabilities by drawing balls from a box. The decisions on allocation were then observed. The relation between customers' characteristics and WTP was also analyzed. A preference for higher frequencies of payouts is recorded. This may derive from a preference for liquidity but also from insufficient self-insuring mechanisms, which would probably be more cost-effective. The more frequent choice of insurance over savings and over participation in risk-sharing groups is another outcome; in 50\% of the villages, insurance is also preferred to cash holdings, possibly due to insufficient remuneration of savings. These results confute the common belief that poor farmers would minimize their expenses and the related insurance coverage. Therefore, in opposition to other studies, the authors maintain that there might be a lack of a suitable offer and of education rather than a lack of demand.

The study by McIntosh et al. (2013) focuses on the use of fertilizers and their relationship with weather index insurance. The study was conducted in 2011 over two years of observations in the Amhara region. Many factors, including credit and insurance availability, are considered. Concentrating on the WTP for insurance, two different research approaches are offered: a survey estimating WTP and the observation of actual purchases. In the estimation, the insurance product was built upon data from the nearby weather station; the prices varied from 50 to 250 ETB. Three options were offered: stand-alone insurance, fertilizers financed with credit, and insurance and fertilizers financed with credit. The outcomes show that being the household head, having greater farmland, or having incurred greater effects of weather shocks in the past positively influence WTP, while the opposite result is registered for credit constraints and the use of coping mechanisms. The price (estimated in $277 \mathrm{ETB}$ ) was very close to the actuarial calculation. A real offer was made through the Nyala Insurance Company (NISCO) 18 months later. Vouchers were provided, implying a subsidy of up to $70 \%$ of the premiums. The take-up rates were low and the WTP was strongly affected by the presence of vouchers and only lightly influenced by a few other variables, such as the precedent use of fertilizer. The behavioral variables or basis risk (probably not well perceived) were not relevant. Although they are not fully comparable, the two approaches show slightly positive or even negative effects. Common with other research is the lack of cash as an obstacle to take-up, which, in fact, is mainly driven by cash vouchers (although not very high $-50 \%$ ). McIntosh et al. (2013) conclude that the product design and fine-tuning is challenging, and the issue of subsidies deserves attention and caution. 
Besides pilot projects, in Ethiopia, the implementations are increasing. Among them is the Ethiopian Project on Interlinking Insurance with Credit in Agriculture (EPIICA) offered by NISCO and Dashen Bank in the Amhara region (McIntosh et al., 2013). Nahu (2011) describes NISCO involvement and other initiatives in Ethiopia, including a weather derivative through which the World Food Programme made the Government of Ethiopia buy coverage by AXA Re in 2006 in order to obtain eventual financial resources for food aid in the case of extended drought. Even if not triggered, proved to be a new strategy for handling the consequences of weather shocks at the governmental level.

Two other products offered by NISCO are the piloting Double Trigger Multiple Peril Crop Insurance (DTMPCI) and the Weather Index Crop Insurance (WICI). The first is an area yield insurance, in which crop loss is measured against different types of risk, among which are rainfall and fire. The first pilot project, in 2007, concerned 120 farmers in Oromia region (Rift Valley area), through a farmer cooperative for teff, wheat, and haricot beans. The product was then extended to other areas and other crops (chickpeas and lentils). The total customers served were 827 of 47,000 potential customers. The second product, offered in 2009, was a simpler WICI, based on weather station data, for smallholder farmers in the Tigray (promoted, as mentioned, by OXFAM) and Oromia (with the World Food Programme) regions. In the two areas, 337 farmers were first served in total, and then increased to 1,368 in 2010 with the extension to the South (SNNP region ${ }^{\mathrm{vi}}$ ), in Amhara region and other areas of the Oromia region. A new pilot project was later promoted for livestock indemnity insurance by the NISCO in collaboration with the Association of Ethiopian Micro-Financial Institutions (AEMFI). Overall, Nahu (2011) lists the weaknesses and strengths of these pilots. Among the first are the lack of awareness by farmers of a suitable regulatory framework and, very importantly, a lack of reliable data. The delivery channels are considered limited, as are insurance companies. Among the positive issues are the increasing attention of the Government to small farmers and the expected establishment of a reinsurance intermediary in Ethiopia. The author concludes by stressing the need to consider other risks faced by farmers. This point is also made by Volpi (2005), with respect to a project of the World Bank in cooperation with the Ethiopian Insurance Corporation (EIC), also quoted by Nahu (2011). Volpi (2005) suggests the reasons why farmers were not so reactive to the proposed insurance contract. After the instruction phase, only 26 farmers in Alaba (a village in SNNP region) bought the contract and more than $50 \%$ did not repeat the purchase. Volpi (2005) stresses the rationality of farmers, who stated that the contract only addressed one important risk, but several other equally important risks affect their vulnerability.

\section{EXPERIMENT AND ADMINISTRATION OF THE SURVEY}

Based on a sample of 120 rural households in the Wolayta zone in Southern Ethiopia (SNNP region), we aim to estimate the willingness to pay for a rainfall weather derivative. The survey was administered by a team of 10 trained enumerators over a period of 3 weeks, in March 2013. The farmers were randomly selected from a larger sample of 360 farmers already involved in a three-year data collection project (2010-2013). ${ }^{\text {vii }}$ The surveyed farmers were from three Kebele. ${ }^{\text {viii }}$ : Hembecchio, Kutto Sorfella, and Abala Faracho . The villages are representative of 3 different agro-ecological zones of the Wolayta area which differ in terms of altitude, rainfall pattern, and households' livelihood strategies. The zones are named by the Ethiopian Ministry of Agriculture after their characteristic crops: the ginger and coffee zone, barley and wheat zone, and maize and root crop zone.

According to the existing literature, preliminary empirical studies on the willingness to pay for crop insurance employ a latent demand approach based on the stated production decisions and risk management strategies of farmers (Fraser, 1992; Gautam et al., 1994; Sakurai \& Reardon, 1997). More recent studies are based on either stated preferences or revealed preferences. In the first case, the preferences are elicited through survey-based techniques, such as contingent valuation methods or conjoint methods (Akter et al., 2009; Heenkenda, 2011; McCarthy, 2003; Patrick, 1988; Sarris et al., 2006; Sherrick et al., 2003). In the other case, data are collected through experimental games, randomized control trials or pilot projects (Clarke \& Kalani, 2011; De Janvry \& Sadoulet, 2013; Dercon et al., 2014; Galarza \& Carter, 2008; Giné et al., 2008; Hill \& Robles, 2011; Hill et al., 2011; Norton et al., 2011; Shawn et al., 2013).

This study is based on an experiment. The pros and cons of experiments are highlighted by both the adopters and users of alternative methods. Their efficacy is challenged by those studies in which the outcomes of experiments and of real life related to WTP show little correlation, as in the case of Hill and Robles (2011) or 
McIntosh et al. (2013). Norton et al. $(2011,2012)$ find the opposite. Despite these caveats, Hill and Veceisza (2010) state that small-scale field experiments are interesting as they may be conducted in an environment in which disturbing effects, such as credit constraints or trust issues, are absent. More importantly, Patt et al. (2009) highlight the learning process triggered by experimental games, which may increase financial literacy and trust. However, distorted behaviors in experiments based on an initial cash endowment must be recalled.

In this study, we use data from a discrete choice experiment in which the interviewees were asked to make a choice out of different choice sets. Discrete choice methods are based on random utility models and allow for heterogeneity in consumers' decisions (Hensher et al., 2005). Unlike traditional stated preference methods, they test for different combinations of price and other attributes and hence provide a better estimate of the demand curve. The theoretical model and the empirical methodology are discussed in detail in the next section.

The study takes a full client's perspective instead of a supply perspective. The objective is to gain a preliminary understanding of the potential clients and estimate the willingness to pay for drought insurance. Neither traditional crop insurance nor other kinds of formal insurance were available at the time when the survey was conducted; informal insurance was widespread. In a separate questionnaire designed for the larger sample, we asked households to provide a definition of insurance and the answers hint that there is very limited knowledge about insurance in general. Besides, in our sample, the percentage of illiterate people was high (34\%). For these reasons, we decided to keep the field experiment as simple as possible. We opted for a weather derivative with a very limited number of attributes, instead of a more complex index-based insurance. Besides, as stated in the previous sections, weather derivatives are more flexible than standard index insurance (Hill \& Robles, 2011).

The hypothetical product offered to the households was not designed according to the real rainfall data and tuned on the basis of households' feedback, but adjusted to a product that was already available in another area of the same region and had proved to be somewhat successful (Hill \& Robles, 2011). The product pays a fixed indemnity when either a moderate or a severe shortage of rainfall occurs. The pilot project implemented by Hill and Robles (2011) was employed as a benchmark in order to build reasonable hypothetical products that households can actually afford. An actuarially fair price is thus unobserved by the researcher, but we can expect that it lies in one or more of the different premium compensation combinations that we considered in the discrete choice experiment. Unlike the project in Hill and Robles (2011) where customers could buy more than one security and for different agricultural months, we allowed the households to buy just one contract that covers each of the two agricultural seasons.

Preliminary focus group interviews in the villages were carried out in order to understand households' perception of drought risk and to outline a shared definition of moderate drought and severe drought. In the second phase, we performed an experiment in which households were faced with eight different choice situations and an extra choice with a strictly dominant alternative to allow for potential inconsistency. In each choice situation, the respondent could opt for one of two different insurance products or the status quo alternative. The experiment complies with orthogonality in the product's attributes (Hensher et al., 2005).

The five categories of the product attributes are: covered season, intensity of drought, supplier, premium, and compensation. In particular, the season category has two levels: Belg, i.e. the small rainy season between the beginning of March and the end of May, and Meher, i.e. the big rainy season between the beginning of June and the end of September. The insurance supplier category comprises: microfinance institution (MFI), farmers' cooperative, informal insurance association (Iddir to use the local name ${ }^{\mathrm{ix}}$ ), and Kebele. 


\begin{tabular}{|c|c|c|c|}
\hline Period of reference & BELG & BELG & \multirow{6}{*}{ NEITHER ם } \\
\hline Intensity of drought & SEVERE & MODERATE & \\
\hline Broker & MFI & IDDIR & \\
\hline Premium & 30 BIRR & 120 BIRR & \\
\hline \multirow[t]{2}{*}{ Payout } & 600 BIRR & 400 BIRR & \\
\hline & $\square$ & $\square$ & \\
\hline
\end{tabular}

Why neither :

Figure 1: Example Of The Choice Set

During the interviews, we asked the households to state their perceived frequency of occurrence of both moderate and severe drought according to the definition provided. We consider the perceived frequency as an extra attribute of the product assuming that the greater the perceived frequency with respect to the frequency implied in the premium-compensation ratio, the smaller the willingness to pay for the insurance product.

\section{METHODOLOGY}

In this section, we present the theoretical approach which describes the household's optimizing behavior regarding the choice among different insurance alternatives. A household $n$ faces a choice among $J$ alternatives in each of T choice situations. We suppose that the utility that the household obtains from choosing alternative $j$ is a linear combination of the insurance product attributes, $x_{n j t}$, and a random term, $\varepsilon_{n j t}{ }^{\mathrm{x}}$ :

$U_{n j t}=\beta_{n}^{\prime} x_{n j t}+\varepsilon_{n j t}$

whereas the attributes are observed by the analyst, the coefficient vector $\beta_{n}$ is unobserved for each $n$ and varies across households with density $f\left(\beta_{n} \mid \Omega\right)$, where $\Omega$ are the parameters of this distribution that are to be estimated. The stochastic element, $\varepsilon_{n j t}$, is also unobserved and different assumptions on its distribution result in different choice models. As is usually common in choice analysis, we impose the condition that $\varepsilon_{n j t}$ is independent and identically distributed (IID) extreme value type 1 (or Gumbel) across all $n, j$, and $t$ (Hensher, Rose, \& Greene, 2005). Conditional on $\beta_{n}$, the logit probability of household $n$ choosing alternative $j$ in the choice situation $t$ is:

$\pi_{n j t}^{s t d}=\frac{e^{\beta_{n}^{\prime} x_{n j t}}}{\sum_{i} e^{\beta_{n}^{\prime} x_{n i t}}}, i=1, \ldots, J$

The standard logit model, as expressed by (2), does not allow for unobserved characteristics that can induce correlation among the alternatives in a choice situation and among the choices over time. The mixed multinomial logit model, i.e. the unconditional logit probability, overcomes these restrictions by allowing for the variance in the unobserved household-specific parameters and, therefore, does not exhibit the property of independence from irrelevant alternatives (IIA) (Revelt \& Train, 1998). The mixed logit probability is:

$\pi_{n j t}^{m i x}=\int\left(\frac{e^{\beta_{n}^{\prime} x_{n j t}}}{\sum_{i} e^{\beta_{n}^{\prime} x_{n i t}}}\right) f\left(\beta_{n} \mid \Omega\right), i=1, \ldots, J$

Equation (3) is a weighted average of the logit formula evaluated for different values of $\beta_{n}$. It follows that the mixed logit probability for the sequence of choices is:

$\Pi_{n j t}^{m i x}=\int \prod_{t}\left(\frac{e^{\beta_{n}^{\prime} x_{n j t}}}{\sum_{i} e^{\beta_{n}^{\prime} x_{n i t}}}\right) f\left(\beta_{n} \mid \Omega\right), i=1, \ldots, J$

In (4), we want to estimate $\Omega$, that is, the population parameters that describe the distribution of individual parameters (Revelt \& Train, 1998). 


\section{HOUSEHOLDS' CHARACTERISTICS}

In the empirical analysis, we include several variables that proxy for households' characteristics in order to allow for further potential heterogeneity in the attributes' coefficient. The data are taken from the larger survey that includes the sample used in this study ${ }^{\mathrm{xi}}$. An important household characteristic should be net income. It is, along with the price, the usual component of demand models. However, we are unable to estimate the net income properly as the current data available do not allow for a proper costing. ${ }^{\text {xii }}$ For that reason, the net income is not included in the analysis.

As an alternative proxy for the household's economic capacity we use the household's net worth, that is, the difference between the total assets and the total financial liabilities. The total assets include agricultural assets, non-agricultural assets, and financial assets. ${ }^{\text {xiii }}$ The financial liabilities are made up of all the outstanding debts. The net worth is also a proxy for the ability of the household to cope with negative shocks and make up for unexpected expenses. However, we do not control for the different liquidity costs of assets. Instead of considering the absolute value of net worth, we test for a non-linear relationship with the insurance take-up probability by taking net worth percentiles.

The land holdings are not considered in the assets since in Ethiopia they are not a household's property. ${ }^{\text {xiv }}$ Farmers commonly establish informal crop-sharing or short-term rent agreements. The size of land is, however, important in the decision regarding which crop to grow and to what extent. When the land does not provide a living, farmers are forced to seek an alternative source of income. We express land holdings in terms of timad, a local unit of land. ${ }^{\mathrm{xv}}$

Age, gender, and the number of family members may proxy for the interviewee's risk aversion. Education can influence the ability to understand the insurance product and appreciate the insurance's utility properly. We consider whether the interviewee is literate and the school grade reached.

Trust and transaction costs may influence financial decisions and be affected by the fact of being a client of a microfinance institution, a member of a local cooperative, or part of one or more Iddirs; therefore, these factors can increase the likelihood of preferring one supplier to another and we test for these effects. Finally, we include some dummy variables to control for the basis risk. In our case, the basis risk is the probability of receiving compensation when the households are not affected by drought or not receiving compensation when they are affected. The dummy variables are built on stated perceptions of how different the rainfall pattern is in the household's field from the location of the weather station and how much more or much less it rains at the weather station than in the household's field.

Table 1 reports all the attribute and control variables. 
Table 1: Variables

\begin{tabular}{|c|c|c|c|}
\hline Variable name & Definition & Unit & Type \\
\hline \multicolumn{4}{|l|}{ Product's attributes } \\
\hline Premium & Cost of the insurance contract & ETB & Integer \\
\hline Indemnity & Expected payment in the case of drought & ETB & Integer \\
\hline Belg & If Belg is the covered season & 0,1 & Dummy \\
\hline Perceived frequency & How often a moderate or severe drought occurs & Years & Integer \\
\hline Cooperative & If a cooperative is the supplier & 0,1 & Dummy \\
\hline MFI & If the MFI is the supplier & 0,1 & Dummy \\
\hline Iddir & If the Iddir is the supplier & 0,1 & Dummy \\
\hline \multicolumn{4}{|c|}{ Household's and interviewee's characteristics } \\
\hline Net worth lower than second centile & Net worth <= ETB 4,055 & 0,1 & Dummy \\
\hline Net worth between second and fourth centile & ETB $4,055<$ Net worth $<=$ ETB 6,902 & 0,1 & Dummy \\
\hline Net worth between fourth and sixth centile & ETB $6,902<$ Net worth $<=$ ETB 11,155 & 0,1 & Dummy \\
\hline Net worth between sixth and eighth centile & ETB $11,155<$ Net worth $<=$ ETB 14,780 & 0,1 & Dummy \\
\hline Net worth greater than eighth centile & Net worth $>$ ETB 14,780 & 0,1 & Dummy \\
\hline Log of landholdings & Household's landholdings & Log(Timad) & Continuos \\
\hline Age & Interviewee's age & Years & \\
\hline Gender & If the interviewee is male & 0,1 & Dummy \\
\hline Number of fam. members & Number of members who live with the head & $\mathrm{N}$. & Integer \\
\hline Illiterate & If the interviewee is illiterate & 0,1 & Dummy \\
\hline Education & Grade reached at school & N. & Integer \\
\hline Cooperative client & If client of at least one cooperative & 0,1 & Dummy \\
\hline MFI client & If client of at least one MFI & 0,1 & Dummy \\
\hline Iddir member & Number of Iddirs of which the $\mathrm{HH}$ is a member & $\mathrm{N}$. & Integer \\
\hline Very different pattern and less rain & $\begin{array}{l}\text { Very different rainfall pattern and less rain on } \\
\text { average }\end{array}$ & 0,1 & Dummy \\
\hline Somewhat different pattern and less rain & $\begin{array}{l}\text { Somewhat different rainfall pattern and less } \\
\text { rain on average }\end{array}$ & 0,1 & Dummy \\
\hline Somewhat different pattern and more rain & $\begin{array}{l}\text { Very different rainfall pattern and less rain on } \\
\text { average }\end{array}$ & 0,1 & Dummy \\
\hline Very different pattern and more rain & $\begin{array}{l}\text { Very different rainfall pattern and more rain on } \\
\text { average }\end{array}$ & 0,1 & Dummy \\
\hline
\end{tabular}

\section{ESTIMATES OF MARGINAL EFFECTS AND WILLINGNESS TO PAY}

A preliminary analysis was carried out considering all the variables listed in Table 1 and their interactions. However, in the final model, we retained only those variables and interactions that turned out to be statistically significant and sufficiently consistent over different model specifications. Table 2 presents the estimation results of the conditional logit (CL) model and the mixed logit (ML) model. The estimate coefficients of the ML are almost all significant and the overall goodness of fit is somewhat higher than in the CL. Besides, the standard deviations of the two random coefficients are statistically very significant and important in size. This suggests that the ML is more appropriate.

The premium coefficient is negative, as expected, and the marginal effect implies that, for instance, an increase of ETB 100 in the insurance price decreases the likelihood of purchasing it by $28 \%$. The price marginal effect accounts for the opposite behavior: a positive coefficient, of high net worth households that, given the average experiment premium, are more willing to purchase insurance by $13 \%$, on average. Unexpectedly, the compensation coefficient is also negative and reflects unobservable motivations. Given that premium and compensation are almost uncorrelated $^{\mathrm{xvi}}$, one reasonable explanation is that the greater the compensation, the lower the trust that the compensation will actually be paid. This outcome deserves some further investigation but may be interpreted as a symptom of farmers' rationality, as explained below.

Despite the majority of households considering Meher to be the most important agricultural season, the results hint that they prefer to insure against a possible drought in the Belg season. The likelihood of choosing insurance that covers the Belg season is greater, on average, by about $6 \%$. There are, however, some differences among households in terms of the preferred season. Households with a net worth between the second and the fourth 
centile along with households that believe that their rainfall pattern is somewhat different from that at the weather station and that it rains more on average tend to prefer Meher. The results for the second and fourth centiles may also be linked to farmers' rationality, according to the controversial effect of wealth on WTP reported in section 2. On the other hand, households that believe that the rainfall pattern on their field is very different from that at the weather station and that it rains less on average tend to prefer Belg. These results suggest that the Belg season is considered more exposed to drought risk.

Table 2: Estimation By Conditional Logit And Mixed Logit

\begin{tabular}{|c|c|c|c|c|c|}
\hline \multirow[b]{2}{*}{ Variable } & \multicolumn{2}{|c|}{ Conditional Logit } & \multicolumn{3}{|l|}{ Mixed Logit } \\
\hline & Estimate & Std Err. & Estimate & Std Err. & Marg. Eff. \\
\hline Premium & $-0.0242 * * *$ & 0.0027 & $-0.0229 * * *$ & 0.0032 & -0.0028 \\
\hline Premium $*$ Net worth greater than eighth centile & $0.0108 * *$ & 0.0043 & $0.0126 * * *$ & 0.0049 & 0.1273 \\
\hline Indemnity & $-0.0183 * * *$ & 0.0019 & $-0.0089 * * *$ & 0.0033 & -0.0012 \\
\hline Belg season & $0.4257 *$ & 0.2522 & $0.8322 * * *$ & 0.3015 & 0.0578 \\
\hline $\begin{array}{l}\text { Belg season * Net worth between second and fourth } \\
\text { centile }\end{array}$ & $-0.9615 * *$ & 0.4254 & $-1.4150 * * *$ & 0.5159 & -0.1056 \\
\hline Belg season * Very different pattern and less rain & 0.6398 & 0.4044 & $0.7637 *$ & 0.4338 & 0.0570 \\
\hline $\begin{array}{l}\text { Belg season * Somewhat different pattern and more } \\
\text { rain }\end{array}$ & $-0.9973 * * *$ & 0.2834 & $-1.1430 * * *$ & 0.3123 & -0.0853 \\
\hline Perceived frequency & 0.0120 & 0.0176 & $-0.3092 * * *$ & 0.0916 & -0.0427 \\
\hline Std dev. perceived frequency & & & $0.2647 * * *$ & 0.0626 & \\
\hline Cooperative & $-0.8737 * * *$ & 0.2501 & $-0.8162 * *$ & 0.3206 & -0.0337 \\
\hline Std dev. cooperative & & & $0.8608 * * *$ & 0.2985 & \\
\hline Cooperative $*$ Illiterate & $0.7645^{* *}$ & 0.3299 & $0.9399 * *$ & 0.4117 & 0.0367 \\
\hline Cooperative * MFI client & $1.1080^{* * *}$ & 0.3299 & $1.3776 * * *$ & 0.4413 & 0.0538 \\
\hline MFI & -0.1021 & 0.3615 & 0.5569 & 0.4645 & Not sig. \\
\hline MFI * Net worth between second and fourth centile & $-1.8004 * * *$ & 0.5081 & $-2.6278 * * *$ & 0.6825 & -0.0916 \\
\hline MFI * Illiterate & $1.2242 * * *$ & 0.3698 & $1.6568 * * *$ & 0.4592 & 0.0577 \\
\hline Iddir & -0.3271 & 0.2875 & 0.1556 & 0.3675 & Not sig. \\
\hline Iddir * Net worth between second and fourth centile & $-1.585 * * *$ & 0.5181 & $-2.2017 * * *$ & 0.6311 & -0.0758 \\
\hline Iddir * Illiterate & $0.6566^{*}$ & 0.3365 & $0.7934 * *$ & 0.3863 & 0.0273 \\
\hline Number of obs. & 1872 & & 1872 & & \\
\hline $\mathrm{LR}-\chi 2$ & $421.74 * * *$ & & $58 * * *$ & & \\
\hline Pseudo-R2 & 0.325 & & 0.371 & & \\
\hline $\begin{array}{l}* * * \text { Significance level at } 1 \% \\
* * \text { Significance level at } 5 \% \\
* \text { Significance level at } 10 \%\end{array}$ & & & & & \\
\hline
\end{tabular}

The lower the perceived frequency (i.e. longer time lag between two occurrences) of drought the lower the likelihood of purchasing insurance; there is a preference for insurance against moderate drought since it recurs more frequently and may be forecast with less uncertainty than a severe drought. This also confirms the farmers' awareness and rationality. Furthermore, poor rural households are probably impatient and discount long-term realizations more than the better-off. For instance, an increase of 3 years in the perceived frequency of drought (i.e. the time intervals between droughts increase) decreases the likelihood of purchasing insurance by nearly $13 \%$ on average. The standard deviation of the perceived frequency is also statistically significant but small, and implies that for $12 \%$ of the surveyed households the coefficient is positive instead.

With regard to the preferred insurance supplier, the results are somewhat uncertain with the only statistically significant coefficient for the cooperative case. If the insurance products were distributed by the cooperative instead of the Kebele administration, the willingness to purchase would decrease by $3 \%$ on average. The standard deviation is also very statistically significant and of high economic relevance. For $39 \%$ of the surveyed households, the coefficient is indeed positive. The cooperative is mostly preferred by illiterate interviewees and MFI clients. The coefficients for the MFI and Iddir variables are both positive but not statistically significant. However, again, illiterate interviewees prefer both the MFI and the Iddir to the Kebele. The opposite occurs for households with a net worth between the second and the fourth centiles. An interpretation of this different behavior is offered below. 
Table 3 presents the average estimates of the marginal willingness to pay (MWTP) for the insurance attributes, computed as the negative ratio of the attribute's coefficient and premium's coefficient. The interaction variables are considered at the mean value. Both standard errors and confidence intervals are constructed with the Krinsky-Robb method, as in Hensher and Greene (2003). First, households would pay a lower premium by ETB 0.46 for every ETB 1 increase in compensation. Second, households would pay about ETB 11 extra for an insurance product that covers the Belg compared with the Meher season; however, the MWTP is not statistically significant. Third, for every one more year in the perceived drought frequency, households would pay a lower premium by nearly ETB 15 on average. Besides, the empirical distribution of the MWTP for the perceived frequency (Figure 2) suggests that it is negative for $87 \%$ of the sample. The remaining $13 \%$ of the sample would pay more for an insurance product against a longer-term drought, such as a severe drought. Fourth, households would pay about ETB 12 less on average if the supplier was a local cooperative instead of the Kebele, but this result is not statistically significant. However, according to the empirical distribution, around $40 \%$ of the surveyed households show a positive MWTP and would pay a higher premium if the supplier was the cooperative. Assuming a $15 \%$ loading on a fair premium of ETB 100, the share of the sampled population that would prefer the cooperative to the Kebele would shrink to about $29 \%$. This result is a consequence of a premium increase. On the one hand, a member of the cooperative can also benefit from the cooperative profits, and should be more willing to participate in covering expenses. However, on the other hand, members' expectation of cost-effectiveness of the cooperative implies that paying a higher premium to cover overestimated administrative costs is considered irrational. Finally, the MWTP of MFI and Iddir attributes are not statistically significant, suggesting that the households are indifferent between these potential suppliers and the Kebele.

The preferences among providers are not straightforward to explain. The still limited knowledge of the MFI by the poorest may induce them to show an undefined preference based more on expectations than on awareness. The poorest may instead prefer the Iddir as poor people, having a smaller amount of assets under risk (Castellani et al., 2013), are its main target. For the total sample, on the contrary, the indifference between Iddir and Kebele in providing insurance may be the outcome of the preference for market solutions over administrative ones and of the awareness of the current limited ability of Iddirs to provide drought insurance to wealthier farmers. The case of the cooperative is more intriguing as it shows opposite signs. Cooperatives are increasingly spreading in rural areas of Ethiopia. Some of them prove to be effective while others show weak management and ability to provide services to members. The outcomes in the sample probably vary depending on the experience of the individual farmers.

Table 3: Estimates Of The Mean, Standard Error, And Confidence Interval Of Willingness To Pay

\begin{tabular}{lcccc}
\hline & & & $95 \%$ confidence interval \\
\cline { 3 - 5 } Attribute & Mean & Std Err. & LB & UB \\
\hline Indemnity & -0.457 & 0.210 & -0.940 & -0.105 \\
Belg season & 11.162 & 12.906 & -14.232 & 36.443 \\
Perceived frequency & -15.403 & 4.721 & -25.309 & -6.612 \\
(Std dev. perceived probability) & 13.231 & 3.581 & 6.889 & 20.976 \\
\hline (Supplier:) & & & -44.546 & 12.571 \\
\hline Cooperative & -12.584 & 14.410 & 12.398 & 80.003 \\
(Std dev. cooperative) & 43.058 & 17.141 & -16.293 & 66.076 \\
MFI & 28.133 & 20.561 & -38.340 & 28.653 \\
Iddir & -1.813 & 17.179 & & \\
\hline
\end{tabular}

Note: The mean and std error were estimated through simulation as in Hensher and Greene (2003) employing 10,000 random standard normal draws. 

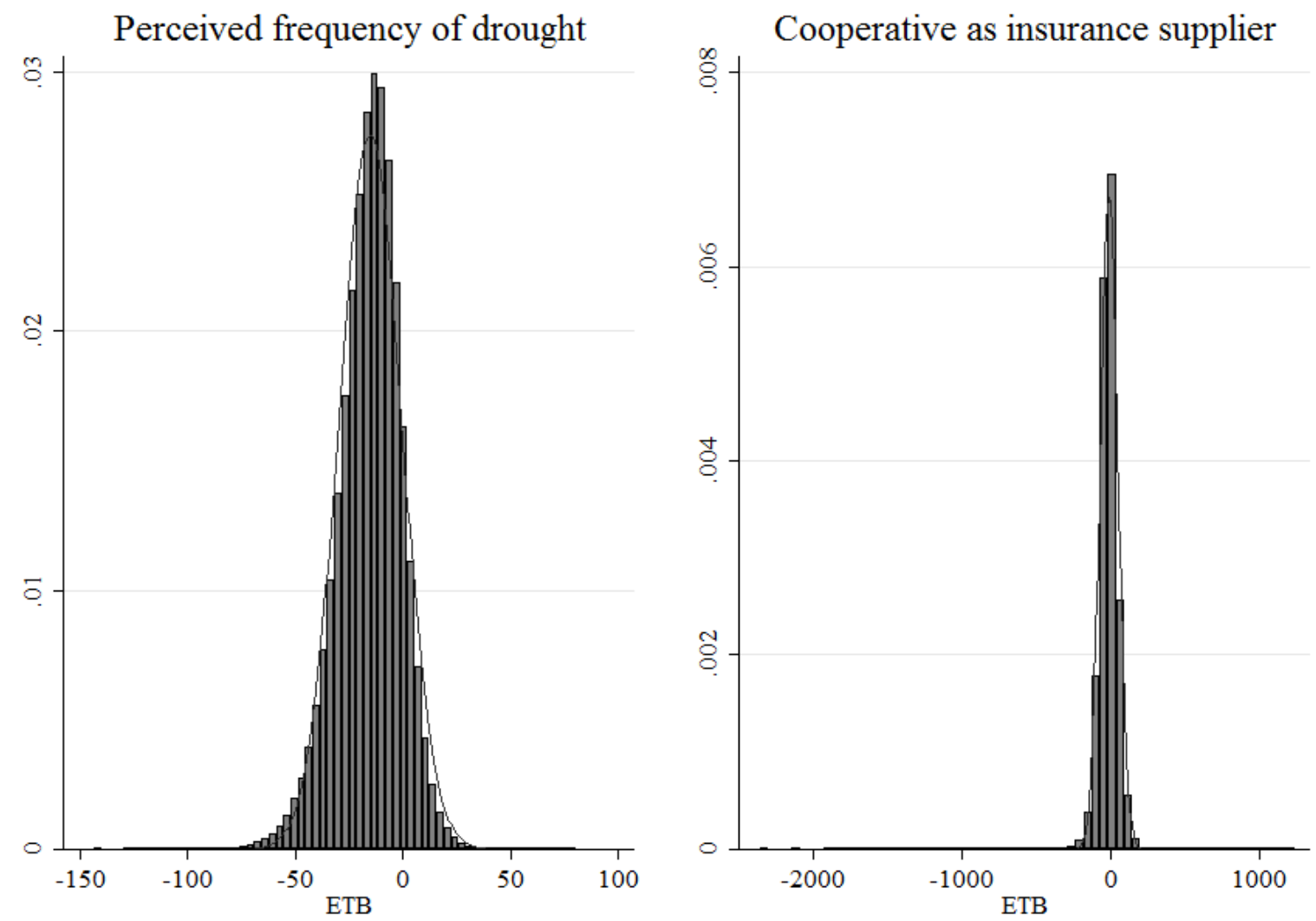

Note: The empirical distribution was simulated following the methodology of Hensher and Greene (2003) employing $5 \mathrm{ml}$ random standard normal draws.

Figure 2: Empirical Distribution Of The Marginal Willingness To Pay For Perceived Frequency Of Drought And Cooperative

\section{STANDARDIZED VS. CUSTOM-MADE INSURANCE PRODUCTS}

Figures 3 and 4 report the distributions of the perceived frequency of moderate and severe drought. The stated frequency of occurrence of a moderate drought is very similar in the 3 villages, with an overall mean of 2.42 years and a standard deviation of 1.03 years. Besides, in two villages the shape of the distributions is also similar. The frequency of severe drought shows some differences which are almost trivial in relative terms. For the severe drought case, the overall mean is 15.39 years and the standard deviation is 7.57 years. The differences are more remarkable looking at the shape of the distributions with a median value between 10 and 20 years.

This preliminary analysis of the perceived frequency supports the design of a sole insurance product against the risk of moderate drought and, with appropriate caution, of severe drought. The design of a suitable product, however, must rely on the comparison between the perceived frequency and the actual rainfall distribution.

We here employ the ML model estimates of Table 2 to assess the attractiveness of hypothetical drought insurance products. We compare an ad-hoc product tailored to the household's perceived drought frequency and different products designed according to a reference frequency. This exercise allows us to estimate the likelihood of purchasing a standardized product (S) against a custom-made product $(\mathrm{CM})$. We take different values as the reference frequency of drought that corresponds, in Figure 3 and Figure 4, to the "All" distribution's mean, mean plus one standard deviation, mean minus one standard deviation, mode, and median.

For every reference frequency $K$ and compensation amount $Y$, we work out the equivalent fair premium (see Table 4) and the market share $(\triangle \mathrm{MS})$ of $\mathrm{CM}$ as the difference in terms of the predicted aggregate likelihood of purchase. The latter is calculated as follows: 
$\Delta M S(k j)=\frac{1}{N} \sum_{i=1}^{N} P(C M \mid K, Y, X)$

where $X$ are the household characteristics that interact with $K$ and $Y$. Since the other product's attributes are the same for both products, they are irrelevant to the decision process.

We find that, as the reference frequency is decreased (i.e. longer time lags), the premium shrinks and the market share of the standardized product grows. Second, when the reference frequency is greater (i.e. shorter time lags) than the average perceived frequency, as the compensation increases, the market share of the standardized product falls. On the contrary, when the reference frequency is smaller than the average perceived frequency, the market share of the standardized product increases along with the compensation. Finally, as the average perceived frequency of drought decreases, such as in the severe drought case, the market share of the standardized product becomes less sensitive to changes in the reference frequency and the amount of indemnity. It follows that, in the design of an insurance product for moderate drought, a small change in the reference frequency and, then, in the fair premium can lead to a big change in the willingness to pay. On the contrary, in the design of an insurance product for severe drought, small changes in the reference frequency barely affect the willingness to pay.

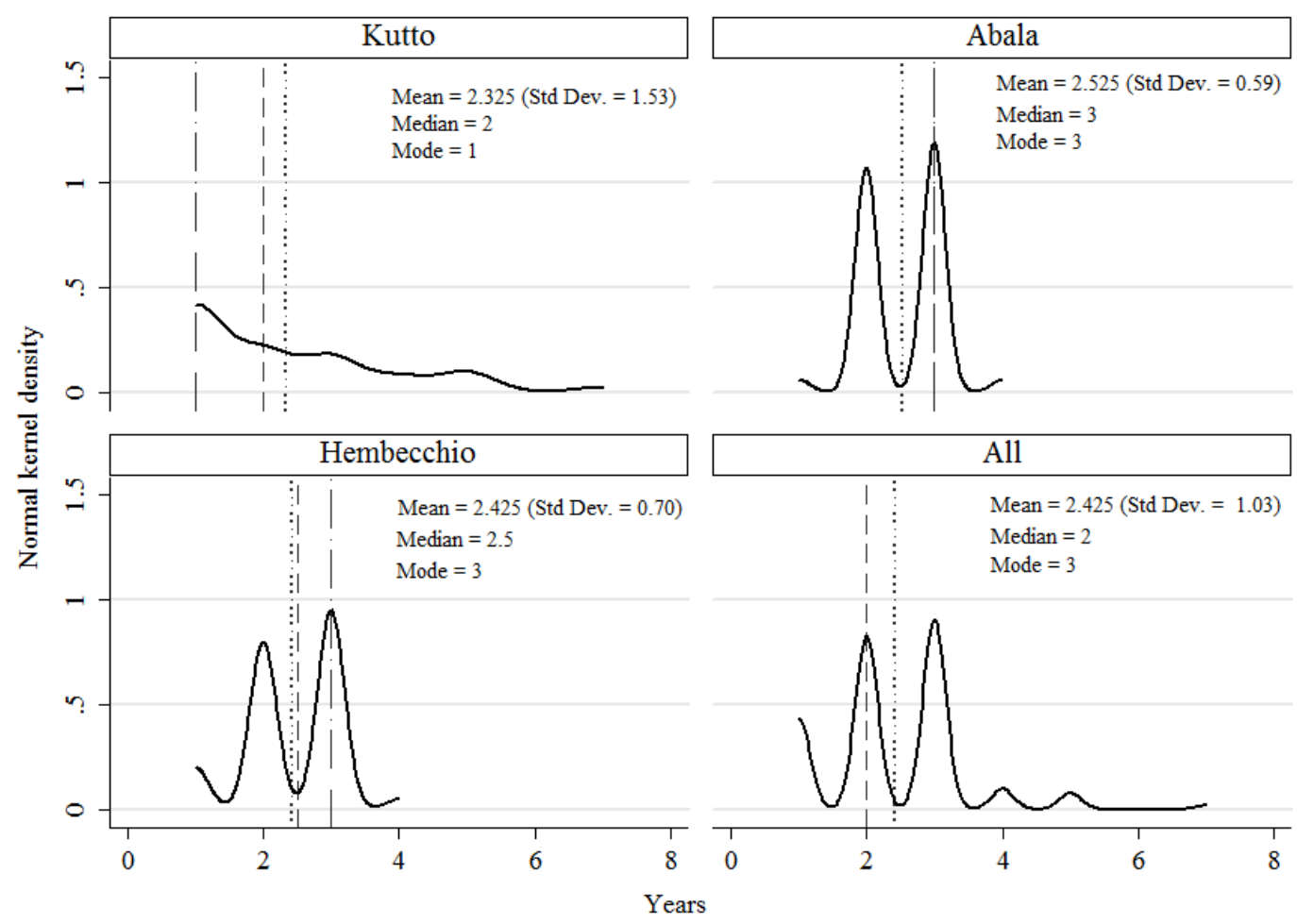

Figure 3: Kernel Distribution Of The Perceived Frequency Of Moderate Drought (In Years) 

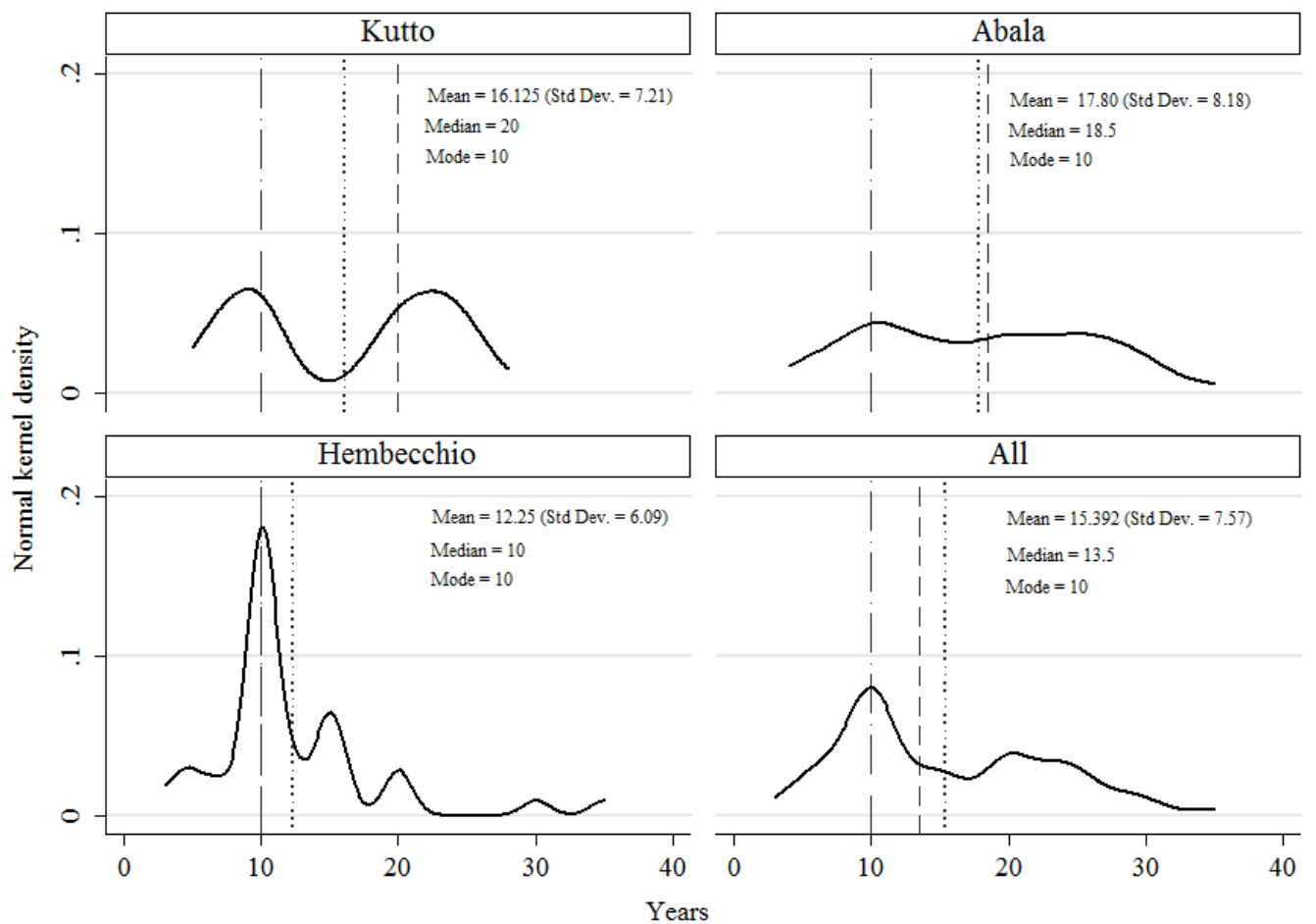

Figure 4: Kernel Distribution Of Perceived Frequency Of Severe Drought (In Years)

Table 4: Reference Frequencies, Indemnities, And Fair Premiums

\begin{tabular}{lllll}
\hline Ref. freq./Ind. & 400 & 450 & 550 & 600 \\
\hline Moderate: & & & & 430.11 \\
1.395 & 286.74 & 322.58 & 394.27 & 300 \\
2 & 200 & 225 & 275 & 247.42 \\
2.425 & 164.95 & 185.57 & 226.80 & 200 \\
3 & 133.33 & 150 & 183.33 & 173.66 \\
3.455 & 115.77 & 130.25 & 159.19 & 76.92 \\
\hline Severe: & & & & 60 \\
7.80 & 51.28 & 57.69 & 70.51 & 44.44 \\
10 & 40 & 45 & 55 & 38.99 \\
13.5 & 29.63 & 33.33 & 40.74 & 26.10 \\
15.39 & 25.99 & 29.24 & 35.74 & 23.92 \\
22.99 & 17.40 & 19.57 & & \\
\hline
\end{tabular}




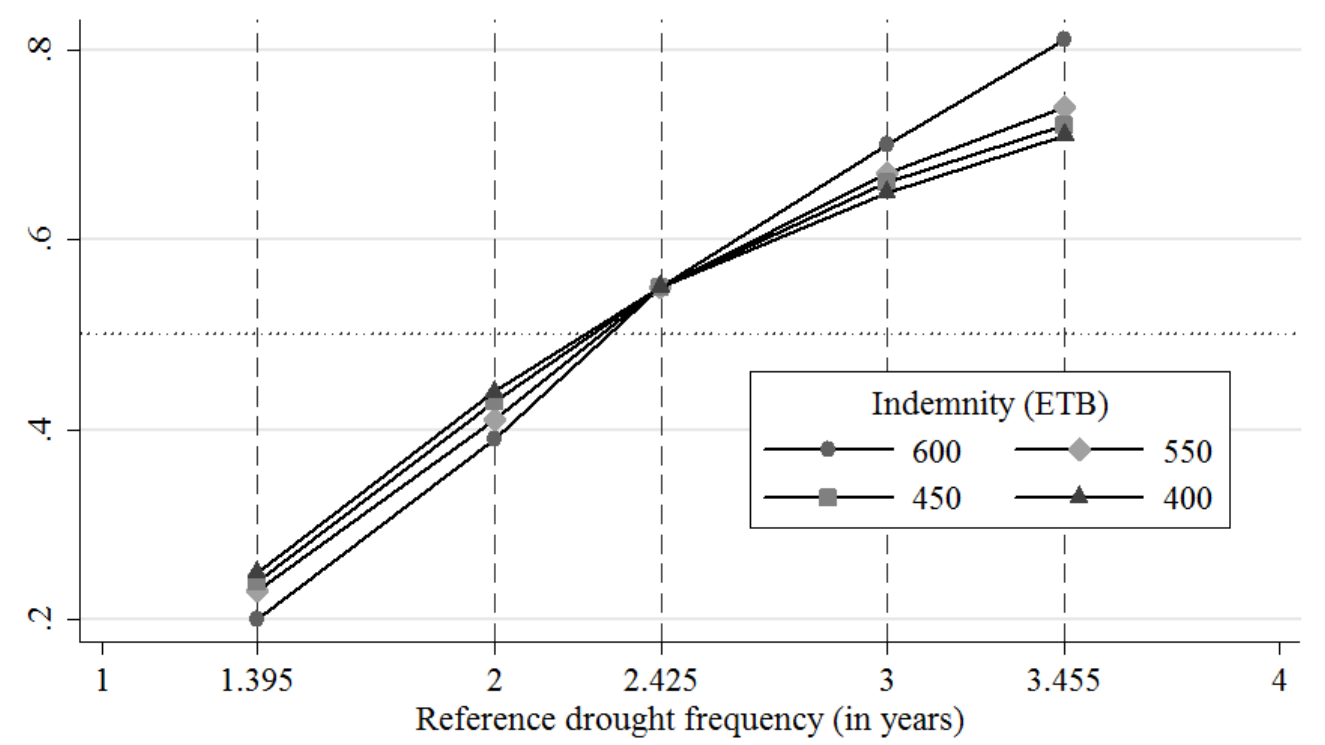

Figure 5: Market Share (Predicted Likelihood) Of Custom-Made Insurance Products Against The Risk Of Moderate Drought



Figure 6. Market Share (Predicted Likelihood)

Of Custom-Made Insurance Products Against The Risk Of Severe Drought

\section{CONCLUSIONS}

Crop insurance against the risk of drought is still in a pilot phase in Ethiopia and most rural households are unaware of formal insurance. We carry out a stated choice experiment in three villages in Southern Ethiopia in order to assess the WTP for a weather derivative product that pays a fixed indemnity if a drought occurs.

We find that the premium, compensation, and perceived drought frequency are important determinants of the insurance take-up. A market simulation analysis suggests that households are more sensitive to premium and compensation changes when the insurance product is against moderate but more frequent drought. Opposite to the case of premium and perceived frequency which show the expected coefficient sign, a negative coefficient is 
counterintuitive for the compensation. Further alternative hypotheses is necessary, but this outcome, coupled with some other observed behaviors, supports the hypothesis of farmers' rational choices, following Clark and Kalani (2011) and Volpi (2005). In fact, the farmers' reluctance to buy protection against larger losses may be the result of perceived unfairness in the premium/compensation ratio, with a consequent low probability to be paid . Other rational choices pertain to the unique behavior of farmers belonging to the second to fourth centiles. This supports the findings of Clark and Kalani (2011) who show that WTP has a non-linear relationship with wealth and Castellani et al. (2013) who suggest that very poor farmers may have nothing at stake in the case of drought, while very rich ones can diversify and need less insurance. The rational logic behind the controversial preference for cooperatives as providers was discussed in the previous section. Further proof of rationality is the overall preference for protection against moderate drought. This is in line with the characteristics of the product offered (a weather derivative) and with the awareness of farmers that forecasts are easier for events occurring more frequently. Lastly, the reticence of the poorest farmers to buy long-term insurance shows awareness of the implicit risk, which makes them discount long-term values at a higher interest rate.

This study adds to the existing empirical literature and provides further insights into the factors that explain the WTP for drought insurance. However, since the experiment in the field relies on a simple hypothetical product, we recommend fine-tuning the analysis, allowing for different payment alternatives and more than one contract ${ }^{\mathrm{xvii}}$ as in the second round of this experiment. Finally, this study suggests caution in designing products and points out the risk implied by standardization of conditions: the take-up, in fact, may be weakened if the products do not meet farmers' expectations.

\section{AUTHOR INFORMATION}

Davide Castellani is a Research Fellow and Adjunct Professor in the Department of Management, Economics and Quantitative Methods at the University of Bergamo in Italy. E-mail: davide.castellani@ unibg.it

Laura Viganò is a Full Professor in the Department of Management, Economics and Quantitative Methods at the University of Bergamo in Italy. E-mail: laura.vigano@unibg.it

Belaynesh Tamre is an Instructor and Faculty of Business and Economics at the Wolaita Sodo University in Ethopia. Email: belsihne2010@gmail.com

\section{ACKNOWLEDGMENTS}

This research was conducted by the "Finance and Development - FinDev" group of the Research Center on International Co-operation of the University of Bergamo in cooperation with Wolayta Soddo University (WSUEthiopia), College of Business and Economics (CBE). The two universities co-financed the research in equal share. The study represents a complementary analysis to the main research project named MicroRiMI (Microfinance, Risk Management and Innovation), through which FinDev has been collecting data - with the cooperation of WSU - in the same area of Ethiopia since 2010. MiroRiMI is sponsored by the University of Bergamo, Giordano Dell'Amore Foundation (Milan), Cariplo Foundation, and Lombardia Region. All the authors contributed to the literature review; in addition, Davide Castellani worked on the experiment design and data analysis and interpretation, Belaynesh Tamire worked on data collection, and Laura Viganò contributed to the experiment design and data interpretation.

\section{REFERENCES}

1. Akter, S., Brouwer, R., Choudhury, S., \& Aziz, S. (2009). Is there a commercially viable market for crop insurance in rural Bangladesh?. Mitigation and Adaptation Strategy of Global Change, 14, 215-229.

2. Berg, E., Schmitz, B., Starp, M., \& Trenkel, H. (2004). Weather derivatives as a risk management tool in agriculture. Presented at the $86^{\text {th }}$ Seminar of the European Association of Agricultural Economists. Anacapri, Italy.

3. Breidert, C., Hahsler, M., \& Reutterer, T. (2006). A review of methods for measuring willingness-to-pay. Innovative Marketing, 2, 8-32. 
4. Bryan, G. (2010). Ambiguity and insurance. (Unpublished job market paper). Yale University Department of Economics. Retrieved from http://aida.wss.yale.edu.

5. Bryla, E., Dana, J., Hess, U., \& Varangis, P. (2003). The use of price and weather risk management instruments. Presented at "Paving the Way Forward for Rural Finance" - An International Conference on Best Practices. Washington, DC: International Trade Center Ronald Reagan Building.

6. Brown, W. (2001). Microinsurance: The risks, perils and opportunities. Small Enterprise Development, 12 , 11-24.

7. Castellani, D., Tamire, B., \& Viganò, L. (2014). The willingness-to-pay for insurance: Evidence from Southern Ethiopia. Presented at the III Congress of the Italian University Network for Development Cooperation (CUCS). Retrieved from http://www.ojs.unito.it/index.php/cucstorino/article/view/530/415.

8. Castellani, D., Chiodi, S., \& Viganò, L. (2013). Are mfis and their customers reactive to disaster risk?: Main topics and four case studies. In R. Manos, J.-P. Gueyie, \& J. Yaron (Eds.), Promoting microfinance: Challenges and innovations in developing countries and countries in Transition (pp. 197-221). New York, NY: Palgrave Macmillan.

9. Clarke, D., \& Dercon, S. (2009). Insurance, credit and safety nets for the poor in a world of risk. DESA Working Papers, 81. Retrieved from http://www.un.org/esa/desa/papers.

10. Clarke, D., \& Kalani, G. (2011). Microinsurance decisions: Evidence from Ethiopia. Presented at the CSAE 25th Anniversary Conference 2011: Economic Development in Africa.

11. Cole, S., Giné, X., Tobacman, J., Topalova, P., Townsend, R., \& Vickery, J. (2009). Barriers to household risk management: Evidence from India. Staff Reports, 373. New York, NY: Federal Reserve Bank of New York.

12. Dalal, A., \& Morduch, J., (2010). The psychology of microinsurance: Small changes can make surprising difference. Microinsurance papers, 5. Geneva: International Labour Office.

13. De Janvry, A., \& Sodoulet, E. (2013). Social networks and the decision to insure (Unpublished working paper). Retrieved from https://bepp.wharton.upenn.edu/bepp/assets/File/AE-S13-Cai.pdf.

14. Dercon, S. (2003). Insurance against poverty. Oxford, UK: Oxford University Press.

15. Dercon, S., Hill, R. V., Outes-Leon, I., Bayrou, A., Clarke, D., \& Taffesse, S. A. (2010). Rainfall insurance and informal groups: Evidence from a field experiment with funeral societies in Ethiopia (Unpublished academic paper). Oxford University, Oxford, UK.

16. Dercon, S., Hill, R. V., Clarke, D., Outes-Leon, I., Taffesse, A. S. (2014). Offering rainfall insurance to informal insurance groups: Evidence from a field experiment in Ethiopia. Journal of Development Economics, 106, 132-143.

17. Elabed, G., Bellemare, M. F., Carter, M. R., \& Guirkinger, C. (2013). Managing basis risk with multiscale index insurance. Agricultural Economics, 44, 419-431.

18. Fafchamps M. (1999). Rural poverty, risk and development. Rome, IT: FAO.

19. FAO. (1992). Glossary of terms for agricultural insurance and rural finance. Agricultural Services Bulletins, 100. FAO, Rome, IT.

20. FAO. (2001). Micro-finance strategy for pastoral risk management. FAO/TCP Discussion notes, 2. FAO, Rome, IT.

21. Fraser, R. (1992). Willingness to pay of crop insurance. Australian Journal of Agricultural Economics, 36, 83-95.

22. Fuchs, A., \& Wolff, H. (2011). Concept and unintended consequences of weather index insurance: The case of Mexico. American Journal of Agricultural Economics, 93, 505-511.

23. Galarza, F. B., \& Carter, M. (2008). Risk preferences and demand for insurance in Peru: A field experiment (Unpublished working paper). Documento de discussion, 11. Universidad del Pacífico, Lima, PE.

24. Gautam, M., Hazell, P., \& Alderman, H. (1994). Rural demand for drought insurance. Policy Research Working Papers, 1383. World Bank, Washington D.C.

25. Gine', X., Townsend, R., \& Vickery, J. (2008). Patterns of rainfall insurance participation in rural India. The World Bank Economic Review, 22, 539-566.

26. Heenkenda, S. (2011). Prospective demand for index-based microinsurance in Sri Lanka. Asia-Pacific Journal of Social Sciences, 3, 1-11.

27. Hensher, D. A., \& Green, W. H. (2003). The mixed logit model: The state of practice. Transportation, 30, 133-176. 
28. Hensher, R. and Greene, W. H. (2005). Applied Choice Analysis: A Premiere, Cambridge, UK: Cambridge University Press.

29. Hess, U. (2003). Innovative financial services for rural India: Monsoon-indexed lending and insurance for smallholders. Agriculture \& Rural Development Working Papers, 9. The World Bank, Washington, DC.

30. Hess, U., Richter, K., \& Stoppa, A. (2002). Weather risk management for agriculture and agri-Business in developing countries. In R. S. Dischel (Ed.), Climate Risk and the Weather Market. London: Risk Books.

31. Hess, U., \& Hazell, P. (2009). Sustainability and scalability of index-based insurance for agriculture and rural livelihoods. Focus 17, Brief 5. International Food Policy Research Institute, Washington, DC. Retrieved from http://www.ifpri.org/publication/.

32. Hill, R. V., \& Viceisza, A. (2011). An experiment on the impact of weather shocks and insurance on risky investment. IFPRI Discussion Papers, 974. International Food Policy Research Institute, Washington, DC.

33. Hill, R. V., \& Robles, M. (2011). Flexible insurance for heterogeneous farmers: Results from a small-scale pilot in Ethiopia. IFPRI Discussion Papers, 1092. International Food Policy Research Institute, Washington, DC.

34. Hill, R. V., Hoddinott, J., \& Kumar, N. (2013). Adoption of weather index insurance, learning from willingness to pay among a panel of households in rural Ethiopia. Agricultural Economics, 44, 385-398.

35. Larson D. F., Varangis, P., \& Anderson, J. R. (2002). Agricultural market and risks: Management of the latter, not the former. Policy Research Working Papers, 2793. The World Bank, Washington, D.C.

36. McCarthy, N. (2003). Demand for rainfall-index based insurance: A case study from Morocco. EPTD Discussion Papers, 106. International Food Policy Research Institute, Washington, D.C.

37. McIntosh, C., Sarris, A., \& Papadopoulos, F. (2013). Productivity, credit, risk, and the demand for weather index insurance in smallholder agriculture in Ethiopia. Agricultural Economics, 44, 385-398.

38. Nahu, S. A. (2011). Weather insurance for farmers: Experience from Ethiopia (Unpublished working paper). Presented at the IFAD Conference on New Directions for Smallholder Agriculture. Retrieved from http://www.ifad.org/events/agriculture/doc/papers/araya.pdf.

39. Norton, M. T., Holthaus, E., Madajewicz, M., Osgood, D. E., Peterson, N., Gebremichael, M., ... Teh, T. (2011). Investigating demand for weather index insurance: Experimental evidence from

40. Ethiopia (Unpublished working paper). Prepared for presentation at the Agricultural \& Applied Economics Association's 2011 AAEA \& NAREA Joint Annual Meeting.

41. Norton, M., Osgood, D., Madajewicz, M., Holthaus, E., Peterson, N., Gebremichael, M., ... Teh, T.-L. (2012). Evidence of demand for index insurance: Experimental games and commercial transactions in Ethiopia (Unpublished working paper). Documento de trabajo. Banco de la Republica, Bogotà, CO.

42. Patrick, G. P. (1988). Mallee wheat farmers' demand for crop and rainfall insurance. Australian Journal of Agricultural Economics, 32, 37-49.

43. Patt, A., Peterson, N., Carter, M., Velez, M., Hess, U., \& Suarez, P. (2009). Making index insurance attractive to farmers. Mitigation and Adaptation Strategies for Global Change, 14, 737-753.

44. Revelt, D., \& Train, K. (1998). Mixed logit model with repeated choices: Households' choices of appliance efficiency level. The Review of Economics and Statistics, 80, 647-657.

45. Sakurai, T., \& Reardon, T. (1997). Potential demand for drought insurance in Burkina Faso and its determinants. American Journal of Agricultural Economics, 79, 1193-1207.

46. Sarris, A., Karfakis, P., \& Christiaensen, L. (2006). Producer demand and welfare benefits of rainfall insurance in Tanzania. FAO Commodity and Trade Policy Research Working Papers, 18. FAO, Rome, IT.

47. Sarris, A. (2013). Weather index insurance for agricultural development: Introduction and overview. Agricultural Economics, 44, 381-384.

48. Shawn, C., Giné, X., Tobacman, J., Topalova, P., Townsend, R., \& Vickery, J. (2013). Barriers to household risk management: Evidence from India. American Economic Journal: Applied Economics, 5, 104-35.

49. Sherrick, B. J., Barry, P. J., Schnitkey, G. D., Ellinger, P. N., \& Wansink, B. (2003). Farmers' preferences for crop insurance attributes. Review of Agricultural Economics, 25, 415-429.

50. Skees, J. R., Varangis, P., Larson, D., \& Siegel, P. (2002). Can financial markets be tapped to help poor people cope with weather risks?. Policy Research Working Papers, 2812. The World Bank, Washington, D.C.

51. Skees, J. R., (2003). Risk Management Challenges in Rural Financial Markets: Blending Risk Management Innovations with Rural Finance. Lead theme paper presented at "Paving the Way Forward for Rural 
Finance” - An International Conference on Best Practices. International Trade Center Ronald Reagan Building, Washington, D. C.

52. Viganò L. (2002). Rural Credit Guarantee Funds: Best Practices, International Experiences and the Case of the NENA Region. Money and Finance in Developing Economies Series, 5. Fondazione Giordano Dell'Amore, Milan, IT: Giuffrè Editore.

53. Viganò L. (Ed.), Aredo, D., Bonomo, L., \& Tsegaye, W. (2007). Risk management, financial innovations and institutional development in rural areas: evidence from the coffee sector in Ethiopia. Bergamo, IT: Bergamo University Press.

54. Volpi, E. (2005). Selling weather insurance to Ethiopian small farmers: A demand assessment and participatory design study (Unpublished Working Paper). Presented at the Annual Meeting of the International Task Force on Commodity Risk Management - The World Bank and SECO.

\section{END NOTES}

${ }^{\mathrm{i}}$ For more details about the advantages and disadvantages of these contracts, besides those quoted here and in the next section on Ethiopia, see Hess (2003), Skees (2003), and Larson et al. (2002).

ii ERHS covered 15 villages and 1,600 households with 7 rounds between 1994 and 2009 in 3 Ethiopian regions. Data used on 378 households refer to the 2009 round and are concentrated on 7 ERHS sites.

iii Subsequently published in 2013 in Agricultural Economics, 44, 385-398.

iv The same study is presented in Norton et al. (2011).

${ }^{v}$ HARITA is promoted by Oxfam America in partnership with Swiss Re and other partners; it subsequently became the R4 Rural Resiliency Initiative, supported by the World Food Programme and the Rockefeller Foundation.

${ }^{v i}$ Southern Nations, Nationalities and Peoples' Region.

${ }^{v i i}$ For more information on this project see http://www.unibg.it/struttura/struttura.asp?cerca=findev microrimi. A short essay on the preliminary outcomes of this study was presented at the III CUCS Congress, Turin. See Castellani et al. (2014).

${ }^{\text {viii }}$ The word Kebele is normally used with two meanings: the local administrative unit (here improperly defined as village) and the local Government authority at the unit level. In the following part, we refer to Kebele as the local Government administration.

${ }^{\text {ix }}$ The hypothesis of using Iddirs as providers relies on the idea of selecting the stronger and more formalized ones.

${ }^{\mathrm{x}}$ Expression (1) is how the utility is usually represented in discrete choice models (Hensher, Rose, \& Greene, 2005).

${ }^{x i}$ See section 4.

${ }^{x i i}$ The estimation of net income is quite a challenge in rural areas, especially as far as expenses are concerned. One single survey is usually insufficient to obtain reliable information. The multiple-survey approach of the MicroRiMI research project can allow for this estimation. The data are undergoing processing.

${ }_{\text {xiii }}$ The non-agricultural assets are: bicycles, motorcycles, radio sets, mobile phones, jewels and watches, tables and chairs, and beds. The financial assets are savings and outstanding credit.

${ }^{\text {xiv }}$ In Ethiopia the land is owned by the Government.

${ }^{\mathrm{xv}}$ Four timad are approximately one hectare.

${ }^{x v i}$ This is due to the way the experiment is designed.

${ }^{x v i i}$ The second experiment was designed according to these lessons learnt, and the data are still under analysis. 